\title{
LA PRECARIEDAD Y SU CONSTELACIÓN LÉXICO-SEMÁNTICA
}

\author{
ANISA AZAOVAGH DE LA ROSA \\ Universidad Internacional de la Rioja
}

(UNIR)

\begin{abstract}
RESUMEN: Este artículo está dedicado a enmarcar la categoría de precariedad en un contexto amplio constituido por un conjunto de autores como J. Butler, G. Vattimo, J. Habermas o M. Nussbaum. Todos ellos convergen, desde intereses diferentes, en rechazar lo que Vattimo denomina «pensamiento fuerte", que proporciona solidez y seguridad teórica, pero que está abocado a justificar la violencia. Frente a este rechazo optan por el «pensamiento débil» que, desde su fragilidad o vulnerabilidad teóricas, es más abierto a una política y una interacción ética no violenta.
\end{abstract}

PALABRAS CLAVE: precariedad; violencia; debilidad; fragilidad; ética.

\section{Precariousness and its lexical-semantic constellation}

ABSTRACT: The aim of this article is to frame the category of precariousness in a broad context constituted by a group of authors such as J. Butler, G. Vattimo, J. Habermas or M. Nussbaum. All of them converge, from different interests, in rejecting what Vattimo calls «strong thinking", which provides theoretical solidity and security, but tends toward justify violence. In front of this rejection, and from its theoretical vulnerability or fragility, they opt for "weak thinking" wich is more open to nonviolent ethical politics and interaction,

KEY WORDS: precariousness; violence; weakness; fragility; ethics.

\section{Aproximaciones lÉXicAS}

Al comienzo de Vida precaria Butler sugiere que es posible «empezar a imaginar un mundo en el que la violencia pueda minimizarse, en el que una interdependencia inevitable sea reconocida como la base de la comunidad política global» ${ }^{1}$. A continuación confiesa "no saber cómo conceptualizar esa interdependencia», limitándose a rechazar desde "nuestra responsabilidad ética y política», su contrario: la «autosuficiencia y soberanía irrestricta» y «un control total» como "valor último», debido a la presencia inevitable de "procesos globales más amplios $»^{2}$. Estos procesos se caracterizan, precisamente, por la interdependencia, uno de los rasgos básicos de la precariedad, pero no el único.

Un diccionario escolar define el término precario como «falto de medios o recursos suficientes», sin especificar de qué tipo, aunque es fácil imaginar que tienen que ver con la subsistencia. Después añade sinónimos como frágil, inseguro, inestable, apurado y los contrapone a estable o suficiente. Si se recurre a Wikipedia p. 14

1 Butler, J., Vida precaria. El poder del duelo y la violencia, Buenos Aires, Paidós, 2006,

2 Ibid., p. 15. 
la perspectiva se amplía. Primero aparece la precariedad en general como «falta de estabilidad o duración», pero enseguida ejemplifica con la precariedad laboral o trabajo precario, vinculado a las condiciones económicas [recursos de subsistencia]. Después hay alusiones a mujeres migrantes, al «precariado» como nueva clase social y a la asociación «jóvenes investigadores precarios» [becarios]. Y a la pobreza. La realidad inmediata que subyace a estas alusiones es, claro está, la crisis económica.

En este contexto se sitúa uno de los últimos trabajos de Butler, un diálogo con la filósofa griega Athena Athanasiou centrado en la desposesión en la que hay que percibir diversas dimensiones. Una es el efecto de ser despojado o desposeído por otros de tus propiedades o pertenencias [trabajo, salario, casa, derechos, etc.]. Y la otra, la acción —actividad o práctica- de desposeer a otros de esas pertenencias o propiedades mediante las políticas neoliberales de recortes que conocemos. Y una tercera es que la desposesión afecta no sólo a propiedades de tipo económico sino también a otras de tipo ético y político, como la dignidad y los derechos básicos ${ }^{3}$.

Unos años antes Butler ya había situado la precariedad en un marco político, sólo que, usando otro sinónimo, «vulnerabilidad, a propósito de la violencia terrorista y contraterrorista que afectó a los Estados Unidos, a partir del 11 de septiembre de 2001. Se refería, entonces, a la vulnerabilidad como el daño, el dolor y la pérdida causados por la violencia, de la que no puede librarse ni siquiera un país tan supuestamente poderoso como los Estados Unidos. En esta situación Butler considera "la vulnerabilidad y la agresión como puntos de partida de la vida política"4, unidas a la "distribución desigual de la vulnerabilidad" que, aunque no lo aclara, seguramente remite a la distribución desigual de los medios y recursos económicos. De lo expuesto se sigue que la vulnerabilidad tiene dos raíces. Una biológica, la mortalidad y su constelación significativa [enfermedad, desnutrición, daños, heridas accidentales, etc.] y una social y política [agresión, expropiación, asesinato, etc.]. Butler da por supuesta la primera, seguramente por ser inevitable, y está más interesada por la segunda porque, cuando menos, es minimizable. Las dos visiones anteriores de la precariedad son coherentes con una tercera más amplia e inclusiva, en la que aparece relacionada con «la vulnerabilidad, la dañabilidad, la interdependencia, la exposición, la persistencia corporal, el deseo, el trabajo y las reivindicaciones respecto al lenguaje y a la pertenencia social». Todo ello como condición necesaria "para ampliar las reivindicaciones sociales y políticas respecto a los derechos de protección, la persistencia corporal y la prosperidad $»^{5}$.

Esta caracterización de la precariedad es, como definición, manifiestamente mejorable, pero este modo de proceder forma parte de la "precariedad metódica» de Butler ${ }^{6}$. En ella no hay un definiens o elemento definicional concreto y preciso,

3 Butler J. y Athanasiou, A., Dispossession. The Performative in the Political, Cambridge, Polity Press, 2013, pp. 1-2 entre otras, y el cap. 1 «The Logic of dispossession and the matter of the human (after the critique of metaphysics of substance)».

4 Butler, J., Vida precaria, o. c., p. 13

5 Butler, J., Marcos de Guerra. Las vidas lloradas, Barcelona, Paidós, 2010, p. 15.

6 Al respecto de esta precariedad metódica véase mi artículo AzAOVAGH DE LA Rosa, A. (2019). Judith Butler y su precariedad metódica. En: Bajo Palabra, II época, no 22. pp. 
al viejo estilo de las definiciones realistas, en el sentido esencialista o sustancialista del término. No propone una «esencia» o una "sustancia» de la precariedad como referentes conceptuales precisos y estables. Al contrario, se sugiere un significado abierto e inclusivo de un conjunto de elementos interconectados pero diferentes vinculados al cuerpo, su vulnerabilidad, su persistencia y prosperidad, todo ello vinculado a la economía, la política, el trabajo, el lenguaje y la pertenencia social. En este sentido, la precariedad es una categoría precaria ella misma en el sentido racional o lógico del término: se trata de una categoría o concepto abierto que se sale fuera del modelo de las ideas platónicas y cartesianas cerradas en sí mismas para salvaguardar su claridad y distinción: su idealidad.

Esta apertura tiene una significación diversa. En primer lugar, está la estructura misma de las definiciones conceptuales que, como sugiere R. Schiappa, son actos o prácticas lingüísticas en las que se solapan dos significados: uno descriptivo o cognitivo y otro valorativo, realizativo o performativo: político y ético ${ }^{7}$. En la caracterización de Butler, la precariedad tiene un significado descriptivo de la vida y la existencia humana en tanto que vulnerable y mortal, pero, a la vez, un significado valorativo que es el que ella resalta. La precariedad es caracterizada negativamente como debilidad y vulnerabilidad o dañabilidad del cuerpo y de la identidad, en la proximidad de la muerte biológica y social; pero, a la vez, es percibida positivamente como lo que nos permite valorar y apreciar la vida humana y acomodar a ella nuestra política y nuestra ética. La precariedad aparece, de este modo, como un criterio político y ético ambivalente o — si se quiere- paradójico y contradictorio. Aparece como exposición a los otros, que pueden herirme y dañarme, pero también comunicarse y dialogar conmigo, y, por lo tanto, como interdependencia de un cuerpo que está disponible para la inclusión y la exclusión en contextos o marcos positivos o negativos: de agresión y violencia, pero también de solidaridad y justicia.

En segundo lugar, la apertura de la noción de precariedad también se debe a que, más que una idea al estilo clásico se trata de una palabra cuyo significado depende, pragmáticamente, de su uso en contextos y para propósitos diferentes como los económicos, políticos y éticos. Como ocurre en el caso de la propia Butler que, en ocasiones, recurre al sinónimo «vulnerabilidad» con el mismo propósito comunicativo o similar. Sinonimia que puede ampliarse a otras palabras como «fragilidad», «debilidad», «inseguridad», «insuficiencia», etc. Todas estas palabras comparten un significado abierto en el sentido precisado para «precariedad»: uno descriptivo y otro valorativo y este ambivalente, negativo y positivo.

147-170. En este artículo se sostiene que el discurso filosófico de Butler no puede no ser precario él mismo. De manera que la obra de Butler en general y, en particular, su ética de la no violencia están atravesadas por la "precariedad metódica».

7 Schiappa, R., Defining Reality. Definitions and the Politicis of Meaning, Southern Illinois University Press, Ill, 2003, p. 176. Ver una aplicación de esta teoría de Schiappa sobre la definición esencialista a algunas que propone Heidegger, en Bello Reguera, G., «Pragmática hermenéutica y ética de la alteridad», en Teresa OÑate y otros (Eds.), Crítica y crisis de Occidente. Al encuentro de las interpretaciones, Madrid, Dykinson, S. J., 2013, pp. 65-66. 


\section{LA PRECARIEDAD ANTROPOLÓGICA Y SU SIGNIFICACIÓN VALORATIVA}

La apertura significativa de la precariedad al universo de la valoración la constituye en una categoría ética que, en principio, es susceptible, de dos aproximaciones. La primera sería como «ética de la precariedad» en el sentido de la ética aplicada: «la ética de $\mathrm{X}$ ", donde "X" puede ser cualquier problema moral como, por ejemplo, la violencia en Butler, la violación o la desigualdad económica. La precariedad aparece como uno de esos problemas y la «ética de la precariedad» sería similar a la ética de la comunicación, de la corrupción, del aborto, etc. En estos casos, la ética aparece como una teoría o trama conceptual independiente de su aplicación y, por tanto, anterior y posterior a ella. Con la precariedad, sin embargo, el problema es más complejo porque la ética no es externa a la precariedad y, por tanto, anterior e independiente de ella, sino que la ética es ella misma precaria, en tanto expresión de la precariedad humana misma, que afecta a sus diversas expresiones o manifestaciones. Entre ellas la ética.

Por esto, la segunda aproximación a la relación entre precariedad y ética tiene que ver con los efectos que podrían seguirse para la ética de ser una expresión o manifestación de la precariedad humana o antropológica. Y al decir "para la ética» me refiero a la trama teórica que la constituye: tanto en su conjunto como en sus elementos conceptuales $^{8}$. En este caso, la expresión «ética de la precariedad» se transforma en esta otra: «la precariedad de la ética» o "ética precaria» o "ética en precario», cuya significación es uno de los problemas a explorar. O no es consciente Butler de la diferencia entre estos dos tipos de precariedad - la antropológica y la ética- o, si lo es, no alude a ella de forma explícita y abierta, aunque está implícita en su obra.

Entre la precariedad antropológica y la precariedad ética hay una relación compleja, como la que existe entre el todo y la parte. El todo sería, en este caso, la precariedad de la vida humana en su totalidad ${ }^{9}$ - vida precaria - de la que la ética sería una parte o aspecto concreto que queda incluida en aquella. Hay un espacio en el que ambas precariedades son lo mismo, precariedad humana o de la vida humana y, a la vez, diferentes, ya que la ética añade a la precariedad humana aspectos no incluidos en sus otras partes. La precariedad ética es diferente de la precariedad orgánica. La precariedad humana es, en su génesis, biológica, genética y neurológica, pero acaba siendo precariedad económica, política, lingüística y cultural, en las que se sitúa la precariedad ética que, a su vez, se diferencia de otras precariedades lingüísticas y culturales como la estética, la política, la religiosa, etc.

En este contexto de identificaciones y diferenciaciones, la precariedad ética o la ética precaria, debe ser matizada ulteriormente y, para ello, lo mejor es relacionarla con aquello de lo que surge: la precariedad humana. Si la vida humana es precaria

8 Se apela así, a la «matriz disciplinal de la ética» cuyos elementos son: el juicio, la acción, el sujeto y los criterios morales éticos y metaéticos. Todos ellos constituyen un «sistema» que persiste más allá de los tiempos y que proporciona a la ética una identidad disciplinal exclusiva y diferenciada de otras. Véase a este respecto Bello Reguera, G. y Azaovagh de LA Rosa, A., «La humanidad como criterio normativo en la obra de Judith Butler». En: Ágora. Papeles de filosofía, 39, $\mathrm{n}^{\circ}$ 1, 2020, pp. 81-98.

9 Por «totalidad humana» entiendo dos cosas: a) la totalidad de un individuo como distinta de sus partes y b) la totalidad de la especia humana en como distinta de sus partes: géneros, culturas, razas, clases, etc. 
de suyo, también lo es su identidad, su responsabilidad y su capacidad de «dar cuenta de sí misma» a la hora de legitimar o deslegitimar racionalmente sus acciones y conductas y a sí misma: en sus identidades y subjetividades. La racionalidad misma es precaria pese a posiciones rotundas y absolutistas como la kantiana, en términos lógico-formales, o su redefinición habermasiana en términos lingüísticos, pragmáticos o comunicativos ${ }^{10}$.

En este punto, la precariedad ética se convierte en metaética, pero metaética deconstructiva, la imposibilidad de proporcionar una idea de validez universalmente obligatoria que se incuestionable o infalible. La ética de la no violencia de Butler, tocada por la precariedad, se convierte ella misma en irremediablemente precaria y surge la pregunta de si una ética precaria es adecuada y pertinente como ética de la no violencia. Butler no aborda este problema de forma explícita y abierta, pero su trabajo sugiere una respuesta afirmativa: una ética no precaria sería un remedio peor que la enfermedad que pretende curar o aliviar: la violencia. Sería ella misma una encarnación de la violencia, una ética violenta que ejemplifica la violencia como tal. De hecho, toda su obra se mueve en el horizonte de una metaética deconstructiva de las categorías fuertes, metafísicas y fundamentalistas, y no en una constructiva o reconstructiva de ellas ${ }^{11}$.

\section{PRECARIEDAD Y DEBILIDAD}

Esta condición de la precariedad se repite o reitera en toda una constelación de categorías afines a la precariedad que, como ella, poseen una significación en parte descriptiva y en parte valorativa, abierta a la ética. En este doble sentido refuerzan y desarrollan cada una a su manera el significado de la precariedad con la que conforman un conjunto o constelación significativa. Han sido puestas en primer plano por autores y autoras recientes lo cual marca una tendencia filosófica inequívoca y entre ellas cabe mencionar: la debilidad, la fragilidad, la vulnerabilidad [otra vez], la finitud, la falibilidad, el riesgo, la humillación, la deconstrucción y la contingencia. La relación de todas estas categorías con la precariedad es doblemente intuitiva. Por un lado, todas se sitúan en la misma posición en relación lógica con sus opuestos binarios como la estabilidad, la consistencia, la fuerza, la dureza, la necesidad [racional], la intemporalidad, la ilimitación, la inmortalidad, la verdad, la racionalidad, la objetividad, etc. Por otro lado, la significación lógica anterior se revela como política entre unas categorías y otras. Unas están situadas en la posición de un poder político fuerte, dominante y violento, autoritario o totalitario, y de una filosofía que se inspira en él y, a la vez, lo legitima; mientras que las otras se sitúan en la posición

10 Por ejemplo, en Habermas, J., Conciencia moral y acción comunicativa, Barcelona, Península, 1985, pp. 137-140.

11 Esta clasificación de la metaética se encuentra en Bello REgUerA, G., «Jacques Derrida: metaética deconstructiva y ética de la hospitalidad», en FERNÁNDEZ AgIS, D., y SiERRA GonZÁLEZ, A., (eds), Aproximaciones a la filosofía francesa del siglo XX, Barcelona, Laertes, 2010, pp. 152-156. Asimismo, ver mi tesis doctoral, «Judith Butler. ética, violencia y precariedad», Universidad de La Laguna, 2016, donde abordo la precariedad butleriana desde el marco de la metaética deconstructiva. 
de lo débil, dominado o sometido por ese poder o bien en una exterioridad resistente y alientan una filosofía crítica, liberada de ese poder hasta donde es posible.

Entre las categorías afines a la precariedad las hay de dos tipos: unas que son a la precariedad humana o antropológica — a la vida precaria - y otras que son a la precariedad ética, un aspecto o parte de esa vida. Y otras a ambas.

Quizá el ejemplo más próximo e ilustrativo sea el de G. Vattimo y S. Zabala y su uso de la debilidad como categoría de referencia. Los autores dejan claras algunas cosas. La debilidad afecta a las vidas humanas débiles, las que han sido excluidas o marginadas por el poder fuerte - político, económico y cultural- de la protección institucional. La debilidad aparece, entonces, en parte como de origen biológico, natural, pero en parte como un efecto político, lo cual la convierte en una categoría biopolítica en la que la dimensión biológica está interferida por la política. En segundo lugar, la debilidad es, a la vez, pensamiento débil, expresión que es, a la vez, filosófica y política. Es filosófica porque Vattimo identifica este pensamiento con la hermenéutica, herencia postmoderrna de Nietzsche y Heidegger, y crítica con la metafísica que, para Vattimo, es el marco tradicional del pensamiento fuerte [objetivo, científico, que él sitúa del lado del poder y la violencia]. Y es política porque el pensamiento débil es el que se sitúa del lado de los débiles, que los autores consideran "el desecho del capitalismo», en su lucha resistente contra los fuertes y su mundo. De la mezcla de una filosofía y una política de la debilidad surge el "comunismo hermenéutico» que Vattimo reivindica en contra del comunismo dictatorial y del capitalismo neoliberal y la «democracia emplazada». Pero no como una opción política a llevar a la práctica, sino como una llamada de atención sobre la continuidad u homogeneidad entre sociedad, política, economía y ciencia tejida o protegida por el poder. En esta situación, construida y defendida por los «vencedores de la historia» la debilidad como categoría filosófica permite, al menos, intentar una interpretación de la historia diferente. Como escriben los autores,

«[...] ningún individuo, grupo o nación débil ha creído jamás que el mundo deba ser como es ni que exista una forma de racionalidad objetiva que haya de ser apreciada, seguida llevada a la práctica. Mientras que la metafísica o, lo que es lo mismo, la política de las descripciones, es la filosofía de los vencedores que aspiran a conservar el mundo tal como es. El pensamiento débil de la hermenéutica se convierte en el pensamiento de los débiles en busca de alternativas» ${ }^{12}$.

La posición de Vattimo y Zabala reitera, con su apuesta por el pensamiento débil ${ }^{13}$, la situación paradójica de la ética de la precariedad: ¿cómo un pensamiento

12 Vattimo G., y Zabala S., Comunismo hermenéutico. De Heidegger a Marx, Barcelona, Herder, 2011, p. 12.

13 G. Vattimo había popularizado la expresión «pensamiento débil» muchos años antes, a raíz de la caída del "comunismo soviético» entre 1989 y 1992, en Vattimo G., y PIER Aldo R., (eds.), Il pensiero débole, Giacomo Feltrinelli Editore, Milán, 1983 (versión castellana como El pensamiento débil, Madrid, Cátedra, 1988). Por su parte, G. VATTIMo volvería sobre la «debilidad» del pensamiento como «desencanto del mundo» (el mundo fuerte o de los fuertes) en su ensayo «Desencanto y disolución» incluido en su Ética de la interpretación, Barcelona, Paidós, 1991. Y, aunque no sea más que una mención, es preciso recordar la conexión de la «debilidad» de Vattimo con otras categorías propias de la tradición hermenéutica como la finitud de Gadamer o la mortalidad de Heidegger en las que no puedo extenderme aquí. 
débil puede ser eficaz en una empresa política de resistencia a un pensamiento fuerte y su proyección política correspondiente? Hago esta pregunta, no para dar una respuesta sino para dejar constancia del problema. Sí añadiré, sin embargo, que, si en aras de la eficacia política el pensamiento débil tratara de hacerse fuerte, se repetiría el gesto del comunismo clásico: convertirse en dictatorial y violento, para hacer frente a la potencia del capitalismo.

\section{PRECARIEDAD y FRAGILIDAD}

Similar al de la debilidad es el recurso a la fragilidad que, como la precariedad, se abre a la humanidad en su totalidad y a la ética en particular, como se aprecia en la siguiente expresión:

[...] los humanos somos frágiles. Lo somos porque en nuestro código genético no tenemos dadas las respuestas para resolver el misterio de la vida que es el enigma del tiempo: el secreto de cómo situarnos en lo que nos acontece y en lo que nosotros mismos somos acontecimiento, la incógnita de cómo construir nuestras maneras de vivir». ${ }^{14}$

En este texto la fragilidad humana es originariamente biológica, genética, pero en ella ya está implícita la fragilidad ética en la alusión a «cómo construir nuestras maneras de vivir» lo cual quiere decir que los genes no las proporcionan y tenemos que inventarlas. En esta línea, el mismo autor añade que «[...] las personas somos frágiles porque sólo llegamos a serlo en tanto que así somos reconocidos por nuestros iguales. Nacemos humanos, pero nos hacemos personas[... ${ }^{11}{ }^{15}$, lo cual sugiere que el reconocimiento es, a la vez, un indicio de fragilidad y un remedio contra ella. Un remedio ético-político. Un remedio que, sin embargo, se articula en términos narrativos o débiles y no epistemológicos o fuertes ${ }^{16}$.

Situados en la ética, es inevitable la mención de «la fragilidad del bien» ${ }^{17}$, expresión que M. Nussbaum incluye en el título de uno de sus primeros libros, desde el que pretende situarse en una posición "humanista», explícitamente opuesta al fanatismo religioso y a la cultura cientificista y tecnocrática y sus expresiones filosóficas y políticas. La fragilidad del bien afecta, por un lado, a la vida humana como vida buena que puede convertirse en trágica por la dinámica emocional o pasional que escapa al control de la razón; y, por el otro, al significado del bien que, en el caso de Aristóteles — el que le interesa a ella- se distanciaría de la Idea platónica, eterna e inmutable, asociada a la seguridad de la verdad y la objetividad metafísica, onto-lógica y epistemológica, e inspiradora del totalitarismo teológico y político; y hace suyo un significado del bien que surge de la interacción política entre los afectados y que, por lo tanto, es pluralista y, como tal, enteramente contingente

14 Rezola, R., Filosofía y fragilidad, Bareclona, Laertes, 2014, p. 15.

15 Ibid., p. 16.

16 Ibid., p. 18.

17 Nussbaum, M., La fragilidad del bien. Fortuna y ética en la tragedia y en la filosofía griegas, Madrid, Visor, 1995. 
y frágil. La relevancia de esta versión del bien no es, obviamente, epistemológica, su criterio no es la verdad, sino política, cuyo criterio es la prudencia. En este sentido, lo que acaba sugiriendo Nussbaum es que el bien es democrático y, por lo tanto, pluralista y frágil, mientras que su versión fuerte, proporcionada por la metafísica platónica, es autoritaria o totalitaria.

La fragilidad es, igualmente, la protagonista de la reflexión crítica de Habermas sobre la eugenesia liberal y las prácticas biotecnológicas como «el diagnóstico prenatal» y otras. Habermas pretende impulsar, desde la ética, el trazado democrático de una línea roja jurídica que dichas prácticas no deben sobrepasar y, en ese marco, aparece la fragilidad humana a la que sitúa como referencia última. En su texto se distingue, por un lado, la "fragilidad de la existencia humana», vinculada a una «imperfecta dotación orgánica» de las cuales se derivan «dependencias y necesidades», especialmente, en períodos de infancia, enfermedad o vejez. A partir de aquí, Habermas entiende el comportamiento moral como «una respuesta constructiva» a esas necesidades y dependencias. Y la regulación normativa de las relaciones interpersonales como una «envoltura protectora» contra las contingencias del «cuerpo vulnerable y la persona encarnada en él» ${ }^{18}$. En esta frase entrecomillada aparece la vulnerabilidad como sinónimo de fragilidad y un poco después el adjetivo "herida» referida a la persona que se expone en unas relaciones con los otros que necesita para «desplegar su identidad y conservar su integridad». Necesidad que, por otro lado, está vinculada a la dependencia respecto de los otros y explica la vulnerabilidad respecto a ellos.

Parece bastante claro que en Habermas la fragilidad biogenética es la que da lugar a la necesidad de las relaciones con los otros en cuyo marco la humanidad se vuelve vulnerable $y$, por otro lado, recurre al reconocimiento del otro como un ser humano valioso y digno para paliar en parte esa vulnerabilidad. A esto lo denomina Habermas «autocomprensión ética de la especie» compartida, según él, por todas las personas morales. Pues bien, en su reflexión sobre la eugenesia liberal, expresa el temor de que los cambios provocados en la ingeniería genética puedan «modificar la autocomprensión ética de la especie" de manera que ya no podamos vernos como seres éticamente libres y moralmente iguales orientados a normas y razones ${ }^{19}$. Habermas, sin embargo, mantiene una diferencia con los autores mencionados antes. Estos se adhieren a una ética débil o frágil, como la humanidad misma, mientras que, como se sabe, la ética que sostiene Habermas es una ética fuerte en el sentido clásico, pese a su redefinición comunicativa de la racionalidad ${ }^{20}$.

En el título del volumen editado por M. Boladeras, mencionado en la nota anterior, aparece otra categoría sinónima de la precariedad, la vulnerabilidad en estrecha relación con la justicia y la injusticia. Dicha categoría es utilizada, además,

18 Habermas, J., El futuro de la naturaleza humana. ¿Hacia una eugenesia liberal?, Barcelona, Paidós, 2002, p. 51.

19 Ibid., p. 60.

20 Una discusión de la posición habermasiana puede verse en CANo Soler, M., «La vulnerabilidad del embrión y el clon» en Habermas, J., El futuro de la naturaleza humana. ¿Hacia una eugenesia liberal? Barcelona, Paidós, 2002 y en Boladeras, M., (ed.), Bioética: justicia y vulnerabilidad, Barcelona, Proteus, 2013, especialmente las pp. 195-196. 
en el título de doce de los veintitrés trabajos que integran dicho volumen, todos en torno a problemas relacionados con la bioética. Elijo dos por su mayor proximidad a la presente investigación.

En el primero de ellos, «Vulnerabilidad, alteridad y responsabilidad», su autora, Janet Delgado Rodríguez, sitúa la vulnerabilidad en el marco de la bioética clínica y propone aplicar la ética de la alteridad de Levinas a las relaciones entre cuidadores y enfermos. La vulnerabilidad es propia del sujeto vulnerable - y, a pesar de ello, autónomo, paradoja que la autora resalta, pero en la que no puedo entrar aquí- y tiene que ver con «la posibilidad de sufrir, con la enfermedad, con el dolor, con la fragilidad, con la limitación, con la finitud y con la muerte ${ }^{21}$. Mención especial merece la responsabilidad para con los enfermos, situados en la posición del otro levinasiano, a la que autora concede relevancia especial. Primero, al caracterizar la responsabilidad como una respuesta a la demanda o interpelación del otro desde su vulnerabilidad y, después, al enfatizar su diferencia con el reconocimiento al que se refería Habermas. Reside, ésta, en el hecho de que el reconocimiento es mutuo entre unos y otros y, por tanto, reciproco o simétrico, mientras que la responsabilidad es asimétrica en la medida en que el enfermo no puede ser responsable de sus cuidadores como ellos lo son de él [cosa que también ocurre entre los infantes y sus padres o sustitutos]. A este respecto, la autora escribe: «la ética exige una generosidad radical del movimiento que va hacia el otro, y por tanto no cabe en Levinas la noción de reciprocidad.» ${ }^{22}$

El segundo de los dos trabajos mencionados se debe a $\mathrm{M}^{\mathrm{a}}$. José Agra Romero quien lo titula «Vulnerabilidad, injusticias y cuidados» y lo sitúa en el mismo marco de la bioética, pero desde una perspectiva más amplia. Agra Romero está interesada en la vulnerabilidad que se presenta como discapacidad y la injusticia de que es objeto, ya que el discapacitado es considerado como una «subespecie» ${ }^{23}$ cuando, en realidad, se trata de una «deficiencia» $\mathrm{o}$ "diversidad funcional» de un individuo humano que, desde luego, encarna la vulnerabilidad de forma significativa ${ }^{24}$. Pero antes de entrar en ello la autora dedica atención especial a la vulnerabilidad como una categoría relevante en el panorama contemporáneo tanto político y mediático como filosófico. Para ello nada mejor que situar la vulnerabilidad en el contexto de la (in)justicia social y política vinculada a la distribución desigual de los recursos y generadora de la existencia de los más débiles y vulnerables y, a la vez, de los cuidados y la protección de que deben ser objeto. En este marco, es inevitable la mención de la crisis económica, tan brutal, en la que la vulnerabilidad está asociada a sufrimientos, desgracias y tragedias que no se deben a causas naturales sino socio-económicas y políticas. A ello se une que la vulnerabilidad también se hace visible en los problemas ecológicos, los desastres naturales y los riegos medioambientales como la inseguridad alimentaria y las epidemias, que constituyen una extensión de la crisis económica y su producción y difusión de vulnerabilidades. Pero lo que, según nuestra autora, ha conferido mayor visibilidad mediática a la vulnerabilidad fueron los atentados del 11 de septiembre de 2001 que asoció la

$21 \quad$ Ibid., p. 396.

22 Ibid., p. 401.

23 Ibid., p. 75.

24 Ibid., p. 50. 
sociedad global a la violencia, el terrorismo y la guerra, con el efecto de inseguridad que ello conlleva y, como añadido, la identificación entre ser vulnerable y ser víctima ${ }^{25}$.

En este punto habría que mencionar la vulnerabilidad migratoria que Gabriel Bello sitúa en el marco de la desigualdad económica Norte/Sur y su cruce con la diferencia cultural Oriente/Occidente, relacionadas ambas, de un modo u otro, con el colonialismo y el postcolonialismo. Teorizada en el marco de la ética de la alteridad de Levinas, entre otras cosas, surge como una crítica radical del racismo ${ }^{26}$. Desde esta perspectiva es posible percibir la vulnerabilidad migratoria como exposición de los emigrantes a todo tipo de «heridas» tanto corporales como identitarias, en una situación de desprotección global. Situación en la que ha insistido $\mathrm{M}^{\mathrm{a}}$ José Guerra Palmero al llamar la atención sobre la diferencia denigrante de las mujeres migrantes de procedencia étnica, expuestas a lo que ella denomina «intersección de opresiones», de género, de clase y de raza que apunta a una feminización de la vulnerabilidad y la precariedad ${ }^{27}$.

Pero volvamos a $\mathrm{M}^{\mathrm{a}}$ José Agra y su incursión en la significación filosófica de la vulnerabilidad, en referencia a autoras como H. Arendt, Adriana Cavarero y Judith Butler. De H. Arendt recupera la asociación de la vulnerabilidad al nacimiento y a la infancia, así como a su condición estructuralmente relacional — dependienteo social y, como tal, expuesta a la violencia hasta punto de poder afirmar que la violencia forma parte de la condición humana. Pero insistiendo en que la violencia incluye no sólo causar heridas sino también curarlas o remediarlas [hasta donde sea posible]: es uno de sus efectos posibles. Si hay cura es porque hay herida y si hay herida es porque ha sido causada por algún tipo de violencia intencional o inintencional. Por eso la vulnerabilidad abre la perspectiva de una ética del cuidado. En este contexto, se recupera la figura del inerme, el que no tiene armas y no puede defenderse de la violencia, es desvalido y pasivo, en posición asimétrica ante la omnipotencia del otro. A partir de esta versión de la vulnerabilidad, $\mathrm{M}^{\mathrm{a}}$ José Agra sitúa algunos ejemplos contemporáneos como la infancia desprotegida - tan abundante en la sociedad global - y la precariedad laboral y económica, derivadas ambas de la distribución diferencial de la vulnerabilidad, de los medios y recursos para vivir como comida, vivienda, trabajo, sanidad, educación, movilidad y protección contra la opresión y otros daños. Todo lo cual le llevará a los problemas de la injusticia y la justicia, la violencia y la protección y el cuidado tanto locales como globales.

En la breve reseña de $\mathrm{M}^{\mathrm{a}}$. José Agra, se muestra como A. Cavarero y J. Butler insisten, cada una a su modo, en la condición relacional y social de la vulnerabilidad humana. Cavarero - que escribe un poco después de la publicación de Vida Precaria de Butler - señala que esta abandona la perspectiva de la vulnerabilidad infantil, expresada como dependencia e insuficiencia existenciales, para centrarse

25 Ibid., pp. 50 y 51.

26 Bello Reguera, G., Emigración y ética. Humanizar y deshumanizar, Madrid, Plaza y Valdés, 2011, pp. 70 y ss.

27 Guerra Palmero, M. J., «Derechos humanos, intersección de opresiones y enfoques crítico-feministas», en Corredor Lanas, C., y Peña Echeverría, J. (coord.), Derechos con razón. Filosofía y derechos humanos, Universidad de Valladolid, 2013. 
en la vulnerabilidad como vulnus o herida, efecto de la exposición del cuerpo a la relación con el otro ${ }^{28}$. En este caso, la vulnerabilidad no sólo es una condición de la infancia, sino también de la vida adulta ${ }^{29}$.

\section{VULNERABILIDAD, VIOLENCIA Y HORRORISMO}

Sobre este marco teórico común, Cavarero y Butler abordan la vulnerabilidad y la violencia contemporáneas desde enfoques diferentes. El de Cavarero es el horror mientras que Butler se queda en el terror y la guerra contra él [war on terror]. Además de las diferencias etimológicas que hacen referencia, respectivamente, a la repugnancia de lo que ocurre en el exterior del cuerpo propio, y al miedo a lo que puede ocurrirle a este cuerpo $^{30}$, Cavarero señala otras de mayor calado, tanto en su materialidad fáctica, cuanto en su significación. Respecto a lo primero, Cavarero argumenta que el terrorismo opera causando la muerte — sobre todo de civiles inocentes e inermes- mientras que el horror lo hace yendo más allá de la muerte. Es lo que ocurre, por ejemplo, en la desfiguración o destrucción de la figura humana, el cuerpo entero, mediante su fragmentación como en el caso de los cuerpos-bomba, que se descuartizan a sí mismos y a los más próximos en la explosión suicida, utilizados como instrumentos de guerra en diversas guerras de Oriente Medio. Y cita las declaraciones de un padre sobre los restos de su hija después de la explosión suicida: «De mi hija había quedado sólo la cabeza... un hombro y un dedito con la uña. Puse todo junto en un paquete. De Aiza no quedaban más que cinco o seis kilos, no más». A lo cual la propia Cavarero añade que

El cuerpo deshecho pierde individualidad. La violencia que lo desmiembra ofende a la dignidad ontológica que la figura humana posee y lo hace inmirable. La cabeza más que cualquier otra parte resulta especialmente repugnante, el resto más marcado humanamente donde el rostro singular aún se muestra ${ }^{31}$.

Sobre esta base empírica, Cavarero da un paso más al usar el horror(ismo) para cuestionar la distinción entre terrorismo y guerra con dos argumentos de indudable peso político. Sostiene, por un lado, que el término horrorismo, que ella introduce, refuta el vocabulario político que aún trata de «adaptar la violencia actual a los viejos conceptos de "terrorismo" y "guerra" ». Y, por el otro, argumenta que el uso de ese término es una "jugada teórica que reclama la atención sobre las "víctimas" sacándosela a los "guerreros" ${ }^{32}$. Además, hace otra aportación significativa al asociar el horror(ismo) a lo que ella denomina «agresividad planetaria» otra manera de referirse a la violencia global, en la que se sitúa el terrorismo [oriental] y la guerra [occidental] contra él, en los que se centra Butler. La expresión de Cavarero es más inclusiva ya que en ella cabe también la violencia sionista contra Palestina

28 Cavarero, A., Horrorismo: Nombrando la violencia contemporánea, Anthopos, Barcelona, 2009, p. 46.

29 Ibid., p. 45.

$30 \quad$ Ibid., pp. 23-24.

31 Ibid., pp. 27-28.

32 Ibid., p. 12. 
[y la reacción violenta de esta], así como la desatada en el interior de los países árabes y entre ellos mismos, sin olvidarse de las dos guerras mundiales del siglo pasado, sobre todo de la segunda, en la que tienen lugar acontecimientos como Hiroshima y Nagasaki o Auschwitz.

La expresión «agresividad planetaria» es utilizada por Cavarero con un significado muy concreto: aquella que tiene por objeto la vulnerabilidad del inerme. El inerme es, como el infante de Arendt, el desarmado o desprovisto de cualquier recurso de defensa, que ejemplifica al máximo la exposición de sí —de su cuerpo y de su identidad - a la agresión y la herida ${ }^{33}$. Pero resulta que hoy el inerme tiene una difusión o diseminación planetarias, ya que cualquiera puede serlo o encarnarlo en cualquier parte, como objeto de la violencia terrorista o contraterrorista ya que ambas alcanzan a la población civil si bien por razones y en circunstancias diferentes. La vulnerabilidad del inerme se convierte, de este modo, en casual o impersonal, lo cual, a juicio de Cavarero, significa una degradación del inerme como un alguien singular en algo impersonal, uno de los rasgos que, desde $\mathrm{H}$. Arendt, define a la humanidad no degradada ${ }^{34}$. Con todo, lo más interesante quizá sea cómo explica la producción del inerme casual o impersonal en la que cabe distinguir dos polos de atención. El primero es la conversión de cierto terrorismo no sólo en guerra sino en guerra santa o sagrada, con lo que cual considera que su violencia es legítima porque defiende lo más valioso: lo que él cree ser la identidad humana. Este terrorismo, en segundo lugar, considera que su enemigo no es una figura concreta, cuya eliminación solucionaría el problema [al estilo de las guerras tradicionales], sino que se trata de un "enemigo absoluto» ${ }^{35}$, el infiel, que no se localiza en un lugar concreto sino que está por todas partes y, sobre todo, en «lugares predilectos» no sólo por el número de víctimas y la difusión mediática, sino porque «cualquiera podría encontrarse allí y a aquella hora ${ }^{36}$. Por tanto, cualquiera o todo el mundo queda paralizado por el terror, convertido en un inerme impersonal cuya singularidad es irrelevante. Por otro lado, esta situación se extiende y se complica por el hecho de que la guerra contra el terrorismo se solapa, arrastrada por él hacia el exterior de sus formas militares tradicionales, en una modalidad de terrorismo absoluto debido a que ella misma no distingue la violencia contra militares de la violencia contra civiles que, en este marco, también son convertidos en inermes "casuales» ${ }^{37}$.

Este sería, aproximadamente, el significado de la expresión «agresividad planetaria» que propone Cavarero como complemento del horrorismo. Con ambas novedades lingüísticas, Cavarero da la impresión de ir un poco más allá de la posición de Butler que aún estaría anclada en la distinción entre terrorismo y guerra. Sin embargo, la posición de Butler no encaja del todo en la crítica de esta distinción por parte de la filósofa italiana. Es verdad que ella se mueve en la órbita de terrorismo y de la guerra contra él, pero cuestiona la legitimidad —moral, jurídica y política - de esta frente a la ilegitimidad de aquél, de modo que, a fin de cuentas, ambos serían ilegítimos. Y, por otro lado, la atención de Butler a las víctimas de

$33 \quad$ Ibid., pp. 43-44.

34 Ibid., p. 127. La cursiva es mía.

35 Ibid., p. 124.

$36 \quad$ Ibid., p. 125.

37 Ibid., pp. 124-125. 
ambos tipos de violencia — del terrorismo y de la guerra, occidentales y orientaleses omnipresente. De lo cual se infiere que la posición de Butler no difiere de la de Cavarero tanto como esta da a entender mediante el uso del término horrorismo. Esta «in-diferencia», además, es ilustrada por la propia Cavarero cuando considera a Auschwitz "el horror extremo», el unicum en el campo del horror y, a la vez, como el terror total ${ }^{38}$, expresión que toma de H. Arendt, una de sus referencias teóricas. Esto sugiere que la distinción entre horror y terror es un poco más borrosa y vaga de lo que Cavarero pretende. Da la impresión, más bien, de que el horror es una de las formas extremas que adopta en terror igual que la tortura, a la que Butler presta atención a propósito de los episodios estadounidenses de Guantánamo y Abu-Ghraib ${ }^{39}$.

\section{BiBLIOGRAFÍA}

Agra Romero, M. J. (2013). «Vulnerabilidad, injusticias y cuidados» en Boladeras, M., (ed.), Bioética: justicia y vulnerabilidad. Barcelona: Proteus.

Azaovagh de la Rosa, A. (2019). «Judith Butler y su precariedad metódica». Bajo Palabra, II época, $\mathrm{n}^{\circ} 22$, pp. 147-170.

Bello Reguera, G. y Azaovagh de la Rosa, A. (2020). «La humanidad como criterio normativo en la obra de Judith Butler». Ágora. Papeles de filosofía, Vol. 39, nº1, pp. 81-98.

Bello Reguera, G., (2011). Emigración y ética. Humanizar y deshumanizar. Madrid: Plaza y Valdés.

Bello Reguera, G., (2010). «Jacques Derrida: metaética deconstructiva y ética de la hospitalidad», en Fernández Agis, D., y Sierra González, A., (eds), Aproximaciones a la filosofía francesa del siglo XX. Barcelona: Laertes.

Bello Reguera, G., (2013). «Pragmática hermenéutica y ética de la alteridad», en Teresa Oñate y otros (Eds), Crítica y crisis de Occidente. Al encuentro de las interpretaciones. Madrid: Dykinson, S. J.

Boladeras, M., (ed.) (2013). Bioética: justicia y vulnerabilidad. Barcelona: Proteus.

Butler J., y Athanasiou, A. (2013). Dispossession. The Performative in the Political. Cambridge: Polity Press.

Butler, J. (2010). Marcos de Guerra. Las vidas lloradas. Barcelona: Paidós.

Butler, J. (2006). Vida precaria. El poder del duelo y la violencia. Buenos Aires: Paidós.

Cano Soler, M. (2002). «La vulnerabilidad del embrión y el clon» en Habermas, J., El futuro de la naturaleza humana. ¿Hacia una eugenesia liberal? Barcelona: Paidós.

Cavarero, A. (2009). Horrorismo: Nombrando la violencia contemporánea. Barcelona: Anthopos.

Delgado Rodríguez, J. (2013). "Vulnerabilidad, alteridad y responsabilidad» en Boladeras, M., (ed.), Bioética: justicia y vulnerabilidad. Barcelona: Proteus.

Guerra Palmero, M. J. (2013). «Derechos humanos, intersección de opresiones y enfoques crítico-feministas», en Corredor Lanas, C., y Peña Echeverría, J., coord., Derechos con razón. Filosofía y derechos humanos, Universidad de Valladolid.

Habermas, J. (1985). Conciencia moral y acción comunicativa. Barcelona: Península.

Habermas, J. (2002). El futuro de la naturaleza humana. ¿Hacia una eugenesia liberal? Barcelona: Paidós.

38 Ibíd., pp. 83 y 77.

39 En «Detención indefinida», incluido en Vida precaria, o. c., y en «La tortura y la ética de la fotografía» recogido en Marcos de guerra, o. c. 
Nussbaum, M. (1995). La fragilidad del bien. Fortuna y ética en la tragedia y en la filosofía griegas. Madrid: Visor.

Rezola, R. (2014). Filosofía y fragilidad. Bareclona: Laertes.

Schiappa, R. (2003). Defining reality. Definitions and the Politicis of Meaning, Southern Illinois University Press, Ill.

Vattimo, G. (1991). Ética de la interpretación. Barcelona: Paidós.

Vattimo G. y Pier Aldo R., (eds.), Il pensiero débole, Giacomo Feltrinelli Editore, Milán, 1983 [versión castellana como El pensamiento débil, Madrid, Cátedra, 1988.].

Vattimo G. y Zabala S. (2011). Comunismo hermenéutico. De Heidegger a Marx. Barcelona: Herder.

anisa.azaovagh@unir.net

Anisa Azaovagh de la Rosa

Universidad Internacional de La Rioja (UNIR)

Departamento de educación

[Artículo aprobado para publicación en enero de 2019] 